\title{
Steroidogenic electron-transfer factors and their diseases
}

\section{Walter L. Miller}

Department of Pediatrics, Center for Reproductive Sciences and Institute for Human Genetics, University of California, San Francisco, CA, USA
Received: 7 August, 2021

Accepted: 11 August, 2021

Address for correspondence: Walter L. Miller

Department of Pediatrics, University of California, San Francisco, San Francisco CA 94143, USA

Email:wlmlab@ucsf.edu https://orcid.org/0000-0002-52454464
Most steroidogenesis disorders are caused by mutations in genes encoding the steroidogenic enzymes, but work in the past 20 years has identified related disorders caused by mutations in the genes encoding the cofactors that transport electrons from NADPH to P450 enzymes. Most P450s are microsomal and require electron donation by $\mathrm{P} 450$ oxidoreductase (POR); by contrast, mitochondrial $\mathrm{P} 450$ s require electron donation via ferredoxin reductase $(\mathrm{FdxR})$ and ferredoxin (Fdx). POR deficiency is the most common and best-described of these new forms of congenital adrenal hyperplasia. Severe POR deficiency is characterized by the Antley-Bixler skeletal malformation syndrome and genital ambiguity in both sexes, and hence is easily recognized, but mild forms may present only with infertility and subtle disorders of steroidogenesis. The common POR polymorphism A503V reduces catalysis by P450c17 (17-hydroxylase/17,20-lyase) and the principal drugmetabolizing P450 enzymes. The 17,20-lyase activity of P450c17 requires the allosteric action of cytochrome b5, which promotes interaction of $\mathrm{P} 450 \mathrm{c} 17$ with POR, with consequent electron transfer. Rare b5 mutations are one of several causes of 17,20-lyase deficiency. In addition to their roles with steroidogenic mitochondrial P450s, Fdx and FdxR participate in the synthesis of iron-sulfur clusters used by many enzymes. Disruptions in the assembly of Fe-S clusters is associated with Friedreich ataxia and Parkinson disease. Recent work has identified mutations in FdxR in patients with neuropathic hearing loss and visual impairment, somewhat resembling the global neurologic disorders seen with mitochondrial diseases. Impaired steroidogenesis is to be expected in such individuals, but this has not yet been studied.

Keywords: Adrenal, Adrenodoxin, Cytochrome P450, Electron transfer, Ferredoxin, Ferredoxin reductase, Mitochondria, Mitochondrial neuropathy, Oxidoreductase, Steroid

\section{Highlights}

Microsomal P450s need P450 oxidoreductase; its mutations cause a form of CAH. Mitochondrial P450s need ferredoxin and ferredoxin reductase (FdxR), also needed for synthesis of iron-sulfur centers. FdxR mutations cause neuropathy, but steroidogenesis in these patients has not been studied.

\section{Introduction}

Steroidogenesis is the process by which cholesterol is converted into biologically active steroid hormones, (mineralocorticoids, glucocorticoids, estrogens, progestins), and also includes the process by which a cholesterol precursor, 7-dehydrocholesterol, is converted into the biologically active form of vitamin D. Most aspects of human steroidogenesis 
were reviewed in 2011, ${ }^{1)}$ and some specialized aspects of steroidogenesis have been reviewed in these pages ${ }^{2-4)}$ and elsewhere ${ }^{5,6)}$; those reviews focus on the biochemistry of the steroidogenic enzymes and the genetics and clinical manifestations of their disorders. Somewhat less attention has been directed toward the electron transfer cofactors required by steroidogenic $\mathrm{P} 450$ enzymes, and to the emerging understanding of their roles and the clinical diseases that arise from their mutation. The best-known and most widely seen example of such a cofactor disease is P450 oxidoreductase (POR) deficiency; much rarer disorders derive from mutations in cytochrome b5 (b5), ferredoxin (Fdx), and ferredoxin reductase (FdxR). To understand these 'cofactor diseases,' we first briefly review the biochemistry and cell biology of steroidogenesis.

\section{Steroidogenesis}

Steroidogenesis is initiated in mitochondria, where cholesterol is converted to pregnenolone by the cholesterol sidechain cleavage enzyme, P450scc, encoded by the CYP11A1 gene. Expression of $C Y P 11 A 1$ renders a cell 'steroidogenic, ${ }^{17)}$ and the level of CYP11A1 transcription determines a cell's maximal steroidogenic capacity. ${ }^{8,9)}$ In adrenal and gonadal cells that produce large amounts of steroids, most cholesterol used for steroidogenesis enters the mitochondria from cytoplasmic stores with the assistance of the steroidogenic acute regulatory protein (StAR), which acts on the outer mitochondrial membrane (OMM) ${ }^{9,10)}$ Other steroidogenic cells, notably those in the placenta, brain and skin, use cholesterol that enters the mitochondria by 'StAR-independent steroidogenesis'; this process is poorly understood, but may entail mitochondrial entry of cholesterol esters, which are freely diffusible across the mitochondrial membranes, ${ }^{10,11)}$ or it may entail other proteins that substitute for StAR, such as placental MLN64. ${ }^{12)}$ Pregnenolone may then exit the mitochondria by diffusion, or may be converted to progesterone by $3 \beta$-hydroxysteroid dehydrogenase, type 2 (3ßHSD2, encoded by the HSD3B2 gene); $3 \beta \mathrm{HSD} 2$ is found in both the mitochondria and endoplasmic reticulum. ${ }^{13)}$ Progesterone is then converted to androgens, estrogens, mineralocorticoids, and glucocorticoids by a series of downstream enzymes including 17a-hydroxylase/17,20-lyase (P450c17, encoded by the CYP17A1 gene), 21-hydroxylase (P450c21, encoded by the CYP21A2 gene), 11 $\beta$-hydroxylase (P450c11 $\beta$, encoded by the CYP11B1 gene), aldosterone synthase (P450c11AS, encoded by the CYP11B2 gene) and aromatase (P450aro, encoded by the CYP19A1 gene). The expression patterns of these enzymes differ in the various types of steroidogenic cells, accounting for their individual patterns of steroidogenesis; the genetics, cell biology, physiology, and human diseases of these enzymes have been reviewed in detail elsewhere.

\section{Cytochrome P450}

Cytochrome P450 enzymes are so named because they absorb light at $450 \mathrm{~nm}$ when the heme iron is reduced; the biochemistry of these enzymes has been reviewed elsewhere. ${ }^{14,15)}$ There are 2 types of human P450 enzymes, type 1 in the mitochondria and type 2 in the endoplasmic reticulum; the human genome encodes 57 cytochrome P450 enzymes, of which 7 are type 1 and 50 are type $2 .{ }^{16)}$ Five enzymes involved in steroidogenesis are type 1 P450s: P450scc, P450c11 $\beta$, P450c11AS, vitamin D 1a-hydroxylase (P450c1a, CYP27B1), and vitamin D 24-hydroxylase (CYP24A1). There are also 4 type 2 P450 enzymes involved in steroidogenesis: P450c17, P450c21, P450aro, and the principal vitamin D 25-hydroxylase (CYP2R1). The biochemistry, cell biology, and clinical physiology of all these enzymes have been reviewed. ${ }^{1,5,6)}$ Both types of P450 require electrons donated by reduced adenine dinucleotide phosphate (NADPH) via an electron-transport chain; the electrons must reach the heme iron atom in the P450, which mediates catalysis, but the electron-transport chains differ for the 2 types of $\mathrm{P} 450{ }^{17)}$

\section{Electron transfer to mitochondrial P450s}

In mitochondria, a pair of electrons from NADPH is accepted by a $54-\mathrm{kDa}$ flavoprotein termed 'ferredoxin reductase' (also termed 'adrenodoxin reductase') encoded by the FDXR gene on chromosome $17 \mathrm{q} 24 .^{18,19)} \mathrm{FdxR}$ is loosely associated with the inner mitochondrial membrane. The flavin adenine dinucleotide (FAD) moiety of FdxR donates the electrons to a $14-\mathrm{kDa}$ protein termed 'ferredoxin' ( $\mathrm{Fdx} 1$, also termed 'adrenodoxin'). The same surface of the Fdx1 molecule interacts sequentially with FdxR and with the recipient mitochondrial

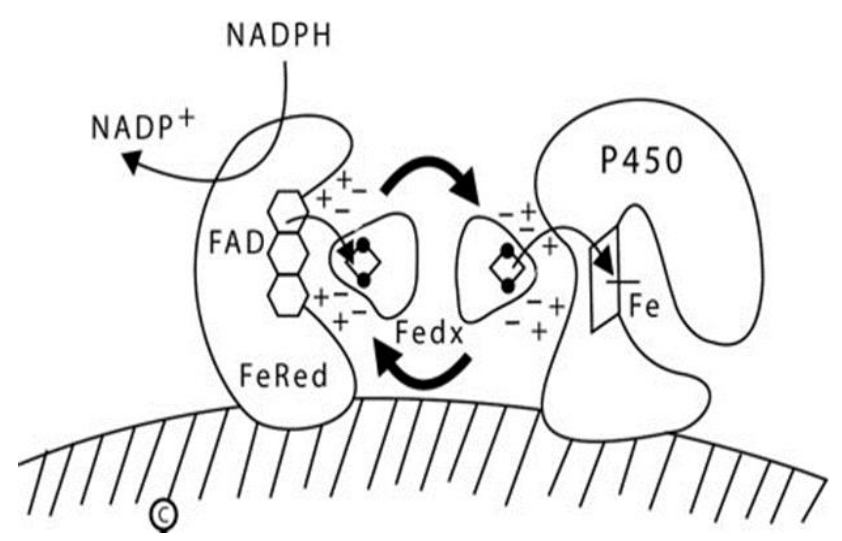

Fig. 1. Diagram of type 1 (mitochondrial) P450 enzymes. The inner mitochondrial membrane is indicated by the hatched area; both ferredoxin reductase (FeRed) and the P450 are membrane bound, but ferredoxin (Fedx) is not. NADPH donates a pair of electrons to the flavin adenine dinucleotide (FAD) moiety of ferredoxin reductase; which then donates them to the $2 \mathrm{Fe} 2 \mathrm{~S}$ center of ferredoxin (depicted by the ball-and-stick image). The same surface of the ferredoxin molecule interacts with both the FAD of ferredoxin reductase and the redox partner binding site of the P450 by electrostatic (charge-charge) interactions. Ferredoxin thus acts as an indiscriminate electron-shuttling protein that can support the catalysis of any available type 1 P450. The electrons reach the heme iron of the P450 permitting catalysis. NADP+, nicotinamide adenine dinucleotide phosphate NADPH, reduced adenine dinucleotide phosphate. 
P450 ${ }^{20)}$ : Fdx 1 forms a 1:1 complex with FdxR, dissociates, then reforms an analogous 1:1 complex with the P450, thus functioning as a diffusible electron shuttle mechanism (Fig. 1). The primary RNA transcript from the FDXR gene is alternatively spliced into 2 mRNA species that can encode proteins differing by 6 amino acids ${ }^{18,19)}$ but only the shorter protein is active in steroidogenesis ${ }^{21}$; it is not known whether the longer form exerts an activity.

\section{Ferredoxins}

Ferredoxin can carry electrons bound to its 'iron-sulfur cluster,' which contains 2 iron atoms and 2 sulfur atoms (2Fe$2 \mathrm{~S}$ ). Iron sulfur clusters can be $2 \mathrm{Fe}-2 \mathrm{~S}, 3 \mathrm{Fe}-3 \mathrm{~S}$, or $4 \mathrm{Fe}-4 \mathrm{~S}$, and are found in many different proteins, such as those in the mitochondrial respiratory chain complexes I, II, and III, where they participate in electron transfer. ${ }^{22}$ The cellular machinery that produces Fe-S clusters, which is highly conserved among eukaryotes, involves 2 major steps: assembly of the Fe-S cluster on a scaffold protein and transfer of the cluster to a recipient protein. ${ }^{23-26)}$ Defects in this process cause numerous diseases, ${ }^{27,28)}$ primarily neurologic disorders such as Friedreich ataxia and Parkinson disease. ${ }^{29)}$ Ferredoxin has been known since the 1960s when it was first identified in bacteria. ${ }^{30)}$ In 1986, the laboratory of Afanasii A. Akhrem in Moscow showed that the amino acid sequences of bovine adrenal 'adrenodoxin' and liver 'hepatoredoxin' were identical ${ }^{31)}$ suggesting there was only one mammalian ferredoxin. Bovine adrenodoxin cDNA was cloned in $1985^{32)}$; human adrenal adrenodoxin ${ }^{33)}$ and placental ferredoxin ${ }^{34)}$ cDNAs were cloned in 1988, revealing identical sequences, showing that the same gene was expressed in both tissues; thus, finding a single gene for adrenodoxin ${ }^{35)}$ was the expected result. The single FDX1 gene is located on chromosome 11q22, with nonexpressed pseudogenes on $20 \mathrm{q} 11-\mathrm{q} 12,^{36,37)}$ and is predominantly, but not exclusively, expressed in steroidogenic tissues. The human genome also contains the related FDX2 gene (formerly termed FDX1L), which encodes Fdx2. The amino acid sequences of Fdx1 and Fdx2 share only $43 \%$ identity and $69 \%$ similarity, yet have very similar 3-dimentional structures ${ }^{38}$; the gene sequences are sufficiently different that the FDX2 gene was not detected in studies of the chromosomal location of the FDX1 gene. ${ }^{36,37)}$ Both forms of Fdx can participate in the synthesis of Fe-S clusters, ${ }^{39-41)}$ but Fdx2 is probably the more important form, especially in the central nervous system, where very little Fdx 1 is found and FDX2 (on chromosome 19p13.2) is well-expressed. Because $\mathrm{Fdx} 1$ is abundantly expressed in steroidogenic tissues (and Fdx2 is not), Fdx 1 is the form of ferredoxin that is principally involved in steroidogenesis.

A human mutation in FDX1 has not (yet) been described, but experimental deletion of the related zebrafish $f d x 1 b$ gene led to defective synthesis of cortisol and androgens. ${ }^{42,43}$ However, there are important differences in the steroidogenesis of zebrafish and human beings, hence the zebrafish results may not indicate what the effects of a human FDX1 mutation would be. However, mutations in both FDX2 and FDXR have been reported recently; mutations in both of these genes yielded neurologic impairments, apparently related to impairment of the synthesis of $\mathrm{Fe}-\mathrm{S}$ clusters, and yielding global mitochondrial dysfunction. Two studies reported a novel mitochondrial muscle myopathy without optic atrophy or reversible leukoencephalopathy (MEOAL) in patients with FDX2 mutations. In the initial report, a 15-year-old girl with MEOAL was born to consanguineous parents; whole exome sequencing identified a homozygous missense mutation in the initiation codon of the FDX1L (FDX2) gene. ${ }^{44)}$ The Fdx2 protein was essentially undetectable in a muscle biopsy and in cultured fibroblasts. Six similar patients from 2 families were homozygous for a Fdx2 missense mutation. ${ }^{45)}$ RNA and protein blotting studies suggested the mutant protein was unstable. The MEOAL phenotype is consistent with impaired formation of Fe-S clusters, which are required by several mitochondrial respiratory chain proteins.

\section{Ferredoxin reductase}

In addition to Fdx 1 and Fdx2 (and many other proteins), the synthesis of $\mathrm{Fe}-\mathrm{S}$ clusters requires FdxR ${ }^{23-26)}$ This recently discovered role of FdxR in Fe-S cluster biosynthesis explains the formerly confusing observation that low levels of mRNA encoding FdxR were found in all tissues, although expression in steroidogenic tissues was about 100 -fold greater. ${ }^{46)}$ The human genome contains only one copy of the FDXR gene encoding FdxR. Because both ferredoxins play a role in the biogenesis of Fe-S centers and there is only one FDXR gene, one would presume that FDXR mutations would also affect Fe-S synthesis and result in a similar phenotype. Knockdown of FDX1, FDX2, or FDXR in human cell lines diminished the synthesis of Fe-S clusters and impaired the activity of several enzymes that rely on Fe-S clusters for activity, as well as depleting cytosolic iron and causing mitochondrial iron overload. ${ }^{40,41)}$ Thus, interference with FDX1, FDX2, or FDXR can disrupt the synthesis or assembly of Fe-S clusters and disrupt cellular iron homeostasis.

Consistent with these observations, 45 patients in 33 families have now been described with mutations in FDXR. ${ }^{47-52)}$ Most of the families are reportedly unrelated to one another, but the high frequency of specific mutations in some studies suggests ether unknown consanguinity or local founder effects. Thus, among the 13 families (26 alleles) in one study, 11 alleles carried the missense mutation $\mathrm{R} 392 \mathrm{~W}^{48)}$ and among 8 families (16 alleles) in another study, 5 alleles carried the missense mutation $\mathrm{P} 372 \mathrm{H},{ }^{52)}$ yet neither of these mutations was detected in any other study. It is noteworthy that all reported patients have at least one FDXR allele that has a missense mutation that retains partial activity; no patient has been reported with null FDXR alleles on both parental chromosomes. The same situation is seen in patients with POR deficiency (see below). Such observations suggest that homozygosity (or compound heterozygosity) for null alleles may be lethal in embryonic or fetal life.

The most consistent clinical findings in FdxR deficiency are 
optic atrophy, neuropathic hearing loss, and developmental delay; some patients had mild movement disorders and even Leigh syndrome with infantile-onset encephalopathy and death. Mice possessing a naturally occurring homozygous R389Q mutation in $F d x r^{53)}$ (corresponding to human R392Q) have a progressive gait disorder, decreased visual acuity, and levels of Fdxr activity at 33\%-50\% of normal, depending on the tissue assessed. ${ }^{48)}$ Consistent with these genetic observations, primary cultures of patient fibroblasts had reduced FdxR activity and increased production of reactive oxygen species, ${ }^{48)}$ and siRNA-mediated knockdown of FdxR in HeLa cells and in human K562 erythroid cells led to iron overload. ${ }^{40)}$ Thus, clinical, genetic, biochemical and cell biologic data show that deficiency of FdxR results in a mitochondrial disorder, primarily manifested in the central nervous system, that shares many features with Fdx2 deficiency and other mitochondrial disorders. However, from an endocrine perspective, the most remarkable feature of all these reports is the absence of any studies directed toward the obligatory role of FdxR in steroid hormone (and vitamin D) synthesis. Future studies should include clinical investigation into adrenal reserve (e.g., by performing adrenocorticotrophic hormone [ACTH] tests) and cell biologic studies of steroidogenesis (e.g., by transfecting nonsteroidogenic cells with vectors expressing a mitochondrial P450 plus either wild type (WT) or mutant FdxR). One might speculate that patients with FDXR mutations that retain partial activity will have compensated adrenal insufficiency, as seen in the nonclassic forms of lipoid congenital adrenal hyperplasia $(\mathrm{CAH})^{54)}$ and P450scc deficiency.

\section{Electron transfer to microsomal P450s}

In the endoplasmic reticulum ('microsomes') NADPH donates electrons to the $82-\mathrm{kDa}, 2$-flavin protein POR, which then donates them to the microsomal steroidogenic P450 enzymes (P450c17, P450c21, P450aro, and CYP2R1) and to the other 46 microsomal P450 enzymes that are involved in the synthesis of eicosanoids and leukotrienes, and in the metabolism of drugs and xenobiotics. ${ }^{16)}$ POR also donates electrons to squalene monoxygenases, fatty acid elongase, heme oxygenase, and $\mathrm{b} 5{ }^{56)}$ This is a 2 -step process. POR has 2 distinct domains that resemble the wings of a butterfly: one wing contains a FAD moiety, and the other contains a flavin mononucleotide (FMN) moiety. These domains are joined by a 'hinge' domain. ${ }^{57)}$ Before interacting with NADPH, POR is in a relaxed, open state. When electrons from NADPH bind to the FAD moiety, POR undergoes a conformational change bringing the 2 'wings' close together, permitting the electrons to travel from the FAD to the FMN; when this happens, the POR then 'relaxes,' permitting the FMN domain to interact with the redox-partner binding site of the P450, thus transferring the electrons to the heme iron atom in the P450, which mediates catalysis (Fig. 2). ${ }^{58)}$

\section{POR deficiency}

The participation of POR in so many essential biochemical functions would suggest that POR deficiency might be lethal, and POR-knockout mice die during fetal development. ${ }^{59,60)}$ Nevertheless, POR deficiency is compatible with human life, causing a severe skeletal malformation syndrome and a form of $\mathrm{CAH}$ characterized by partial (and variable) deficiencies in the activities of P450c17, P450c21, and P450aro. ${ }^{61,62)}$ The associated skeletal malformation syndrome is a form of Antley-Bixler Syndrome (ABS), which is characterized by craniosynostosis, brachycephaly, radio-ulnar or radio-humeral synostosis, bowed femora, arachnodactyly, midface hypoplasia, proptosis, and choanal stenosis. The ABS phenotype can be caused either by recessive POR mutations or by dominant, gain-of-function mutations in fibroblast growth factor receptor 2 (FGFR2). ${ }^{62)}$ When ABS is seen in association with abnormal steroids and ambiguous genitalia in either sex, the cause is POR; when ABS is seen without disordered steroidogenesis or genital development, the cause is FGFR2. The ABS phenotypes resulting from POR or FGFR2 mutations are indistinguishable, even though the mutations in the POR and FGFR2 genes segregate completely. ${ }^{62)}$ The ABS skeletal phenotype in patients with POR deficiency probably results from diminished activity of CYP26B1, the POR-dependent microsomal enzyme that degrades retinoic acid. ${ }^{63)}$ Studies of 2 families with CYP26B1 mutations and the recreation of their mutations in transgenic mice and zebrafish show that retinoic acid must be degraded locally in the embryonic connective tissues that form skeletal joints and

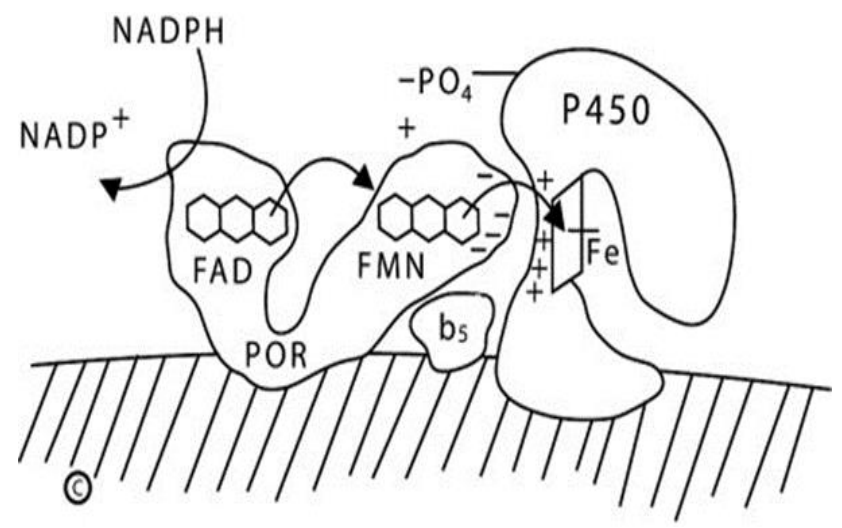

Fig. 2. Diagram of type 2 (microsomal) P450 enzymes. The endoplasmic reticulum membrane is indicated by the hatched area; both $\mathrm{P} 450$ oxidoreductase (POR) and the P450 are membrane-bound. NADPH interacts with the flavin adenine dinucleotide (FAD) domain of POR and donates a pair of electrons to the FAD moiety. Electron receipt elicits a conformational change, permitting the isoalloxazine rings of the FAD and flavin mononucleotide (FMN) moieties to come close together, permitting the electrons to transfer from the FAD to the FMN. Electron receipt by the FMN reverts the POR protein to its original, open conformation, permitting the FMN domain to interact with the redox partner binding site of the P450 by electrostatic charge interactions. The electrons reach the iron atom of the heme group of the P450, permitting catalysis. For some reactions catalyzed by some $\mathrm{P} 450$ enzymes, notably the 17,20-Iyase activity of human P450c17, cytochrome b5 acts allosterically to promote increased activity. NADP+, nicotinamide adenine dinucleotide phosphate; NADPH, reduced adenine dinucleotide phosphate. 
sutures; POR deficiency disrupts CYP26B1 activity, accounting for the skeletal phenotype. Other mechanisms, including defective signaling by hedgehog proteins secondary to a PORassociated defect in cholesterol synthesis may also play a role. Dozens of human POR mutations have now been described, affecting various P450 enzymes to differing degrees, explaining the great variability in the clinical and hormonal findings in POR deficiency.

POR deficiency has different steroidal phenotypes, depending on the specific POR mutation(s). Impaired P450c21 activity may lead to circulating concentrations of $17 \mathrm{OH}$-progesterone that are high enough to trigger newborn screening programs for $\mathrm{CAH}{ }^{61,62,64,65)}$ Most patients with POR deficiency have normal electrolytes and normal basal cortisol concentrations that respond poorly to $\mathrm{ACTH}$, indicating compensated adrenal insufficiency ${ }^{61,62,66,67)}$ POR deficiency, usually when sufficiently severe to result in ABS, can cause genital ambiguity: males may be underdeveloped and females may be virilized. Androgen synthesis is typically impaired in POR deficiency by the effect of POR mutations to diminish the 17,20-lyase activity of P450c17, as this activity is especially sensitive to impaired electron transport. ${ }^{17,68,69)}$ Thus, males with POR deficiency are hypoandrogenic; those with severe POR defects have underdeveloped external genitalia, and those with milder defects may only have infertility. ${ }^{62,64,65)}$ Females with POR deficiency may be partially virilized by 2 mechanisms. First, some (but not all) POR mutations that cause ABS will result in partial deficiency of placental aromatase (P450aro) activity, resulting in fetal virilization similar to that seen with P450aro deficiency. ${ }^{61,62)}$ This is the usual outcome among infants carrying the R457H mutation (prevalent in Japan), but not with the A287P mutation (prevalent in Europe). ${ }^{61,62,66,70)}$ Women carrying a fetus with POR R457H have low estriol levels, ${ }^{71,72)}$ and the R457H mutant does not support P450aro activity in vitro, whereas the A287P mutant retains full in vitro activity with P450aro. ${ }^{73)}$ Second, POR deficiency drives steroid precursors into the alternative "backdoor" pathway of androgen biosynthesis, ${ }^{74)}$ converting fetal 17OHP to androgens. ${ }^{72,75}$ The relative importance of these 2 mechanisms for virilizing the fetus with POR deficiency varies with the specific POR mutation involved.

\section{POR genetics and regulation}

The single human POR gene, located on chromosome 7 , consists of 15 protein-coding exons and a first untranslated exon that lies $\sim 39 \mathrm{~kb}$ upstream and initiates transcription. The POR gene is highly polymorphic: among 842 persons from the San Francisco area who identified themselves as AfricanAmerican (AA), Caucasian-American (CA), Mexican-American (MA), or Han Chinese (Asian) American (AS), there was a high degree of polymorphism, including 140 single nucleotide polymorphisms present in $>1 \%$ of 1 of the 4 populations. ${ }^{76)}$ By far the most common polymorphism resulted in an amino acid change (A503V), which was found on $19.1 \%$ of AA alleles, $26.4 \%$ of CA alleles, $31.0 \%$ of MA alleles and $36.7 \%$ of AS alleles (overall incidence of $27.9 \%$ of all alleles) ${ }^{76)}$ There did not seem to be any selection for this variant, as it was in Hardy-Weinberg equilibrium.

Rat POR transcription requires thyroxine acting through a thyroid-response region at bases -564 to $-536 .{ }^{77,78)}$ Computational searches of $10 \mathrm{~kb}$ of 5 flanking DNA in the human POR gene identified no conserved regions $>2.5-\mathrm{kb}$ upstream, and no apparent transcription factor binding sites more than 0.9-kb upstream from the transcriptional start site..$^{79)}$ Most basal transcriptional activity in the human POR promoter lies within $325 \mathrm{bp}$ from the untranslated exon. This region contains common polymorphisms at $-208,-173$, and $-152 .^{76)}$ Among these 3 polymorphisms, only the one at -152 reduced transcription (by $65 \%$ in human adrenal NCI-H295A cells). ${ }^{79}$ Electrophoretic mobility shift assays identified binding of Smad3/Smad4 between -249 and -261 and binding of thyroid hormone receptor- $\beta(\operatorname{TR} \beta)$ at $-240 /-245$, but did not detect proteins binding to either the WT or polymorphic sequence at -152. Chromatin immunoprecipitation confirmed that Smad3, Smad4, TR $\alpha, T R \beta$, and estrogen receptor- $\alpha(E R \alpha)$ bound the POR promoter between -374 and -149. Co-expression of these transcription factors and POR promoter-reporter constructs followed by treatment with estradiol or triiodothyronine showed that triiodothyronine exerts major tropic effects via TR $\beta$, and that TRa, ERa, Smad 3 and Smad 4 exert lesser, modulatory effects. ${ }^{79)}$ Thus, TR $\beta$ and $S m a d 3 / 4$ are key factors in human POR expression, and the common polymorphism at -152 may play a role in genetic variation in steroid biosynthesis and drug metabolism.

\section{POR and drug metabolism}

Because POR is required by all drug-metabolizing P450 enzymes, there has been considerable interest in the potential impact of POR allelic variations on drug metabolism. Among the 140 human POR SNPs, only 2 were found in $>2 \%$ of the population: these were the coding sequence variant $\mathrm{A} 503 \mathrm{~V}$ and the $\mathrm{C}$ to $\mathrm{A}$ change at -152 in the promoter. ${ }^{76)} \mathrm{A} 503 \mathrm{~V}$ was the most common allelic variant. The activity of POR A503V has been assayed by measuring the parameter $\operatorname{Vmax} / \mathrm{Km}$ for the activity of a P450 enzyme compared to P450's activity with WT, control POR. The activity of A503V to support catalysis by steroidogenic enzymes varied: A503V had 68\% of WT ability to support the 17 -hydroxylase activity of human P450c17 and $58 \%$ of WT ability to support its 17,20-lyase activity. ${ }^{62,76)}$ By contrast, A503V had $80 \%$ of WT activity to support the 21-hydroxylation of progesterone by human P450c21, and $95 \%$ of WT ability to support the 21-hydroxylation of $17 \mathrm{OH}$ progesterone. ${ }^{80)}$ Thus, POR A503V may contribute to reductions in androgen synthesis by $\mathrm{P} 450 \mathrm{c} 17$ but has minimal impact on the activity of P450c21. Furthermore, these studies show that the ability of a POR variant to support the activity of one P450 enzyme does not predict its ability to support the activity of other P450 enzymes.

A survey of 35 POR variants with the human hepatic 
enzymes CYP1A2 or CYP2C19 found substantial differences among the POR variants studied, including some (notably Q153R) that increased activity. ${ }^{81)}$ The human hepatic enzymes CYP3A4 and CYP2D6 respectively metabolize $45 \%$ and $\sim 25 \%$ of clinically-used drugs ${ }^{82,83)}$; studies addressed their activities with the common A503V variant, the common disease-causing mutants A287P and R457H, and the Q153R gain-of-function mutant. CYP3A4 can metabolize a huge array of drugs because it can alter its shape to accommodate the substrate. Crystallography shows that human CYP3A4 has the same fold as other P450 enzymes, but that its substratebinding pocket is highly distensible: it has a volume of $\sim 520 \AA^{3}$ in the absence of substrate or in association with metyropone (212 Da) or progesterone $(318 \mathrm{Da}),{ }^{84)}$ but expands to $\sim 2,000 \AA^{3}$ when binding erythromycin $(734 \mathrm{Da}){ }^{85)}$ To survey the potential impact of such substrate-induced conformational changes in CYP3A4 on electron donation from POR, the ability of WT, Q153R, A287P, R457H, and A503V POR to support catalysis by CYP3A4 was assessed using 4 substrates: testosterone (288 Da), midazolam (326 Da), quinidine (324 Da) and erythromycin $(734 \mathrm{Da})$, representing drugs of different sizes and chemical classes (Table 1$){ }^{86)}$ When the $6 \beta$-hydroxylation of testosterone by CYP3A4 was supported by POR Q153R, it had 129\% of WT activity. With POR A287P it had 17\% of WT activity, with POR R457H activity was barely detectable, and with POR A503V it had 77\% of WT activity. CYP3A4 metabolizes midazolam by both 1-hydroxylation and 4-hydroxylation. When supported by POR Q153R, CYP3A4 had 92\%-94\% of WT activity for these activities; POR A287P supported $14 \%-17 \%$ of WT activity, R457H supported minimal activity, and POR A503V supported 61\%-74\% activity. Quinidine has 2 fused rings, and is 3-hydroxylated by CYP3A4; when supported by POR Q153R, CYP3A4 activity was 150\% of WT activity, POR A287P, and R457H supported barely detectable activity, and POR A503V supported 89\% of WT activity. CYP3A4 catalyzes $\mathrm{N}$-demethylation of erythromycin; to accommodate erythromycin, the substrate-binding pocket of CYP3A4 expands substantially. POR Q153R, which shows increased activity in other circumstances, had only $76 \%$ of WT activity to support CYP3A4 metabolism of erythromycin. A287P and $\mathrm{R} 457 \mathrm{H}$ supported minimal activity, but A503V had full WT activity to support the metabolism of erythromycin by CYP3A4. Thus the ability of different POR variants to support the activity of CYP3A4 varies with the substrate: both substrate size (as evidenced by erythromycin) and chemical structure (as evidenced by midazolam) are important. ${ }^{86}$ Similar studies examining the ability of POR variants Q153R, A287P, R457H, and A503V to support 3 activities catalyzed by CYP2D6 (activation of EOMCC, O-demethylation of dextromethorphan and 1-hydroxylation of bufuralol) again showed decreased activity of A503 $\mathrm{V}^{87)}$ Thus, A503V shows reduced activity to $\sim 60 \%$ of WT in many, but not all assays, underscoring the need to test each reaction of interest (Table 1). These data have been reviewed previously. ${ }^{88)}$

\section{Cytochrome $b_{5}$}

\section{Promotion of $\mathrm{P} 450$ activities by b5}

Cytochrome $\mathrm{b}_{5}$ (b5), encoded by the CYB5A gene on chromosome $18 \mathrm{p} 13$, is a small heme-containing protein found in 3 forms. ${ }^{89,90)}$ The 98 amino acid cytosolic form is mainly expressed in erythrocytes, where it reduces methemoglobin to hemoglobin, while the 134 amino acid endoplasmic reticulum form and the 146 amino acid form found on the OMM are widely expressed, including in steroidogenic tissues. ${ }^{91)}$ Cytochrome b5 has 2 domains: one binds heme and the other forms a structural core, from which the C-terminal membraneanchoring helix extends. The surface of the heme-binding domain has numerous negatively charged residues that facilitate electrostatic interactions with other proteins. Cytochrome b5 can augment some P450 activities, possibly involving direct electron transfer from b5 to the P450. ${ }^{92)}$ However, some of the actions of $\mathrm{b} 5$ can be observed with apo-b5, which lacks its heme

Table 1. Activities of P450 oxidoreductase (POR) variants in various assays

\begin{tabular}{|c|c|c|c|c|c|c|c|c|c|c|c|c|}
\hline \multirow{3}{*}{$\begin{array}{l}\text { POR sequence } \\
\text { variants }\end{array}$} & \multicolumn{12}{|c|}{ CYP } \\
\hline & \multicolumn{3}{|c|}{ 2D6 } & \multicolumn{5}{|c|}{$3 A 4$} & \multirow{2}{*}{$\frac{1 \mathrm{~A} 2}{\mathrm{EOMCC}}$} & \multirow{2}{*}{$\frac{2 \mathrm{C} 19}{\text { EOMCC }}$} & \multicolumn{2}{|c|}{17} \\
\hline & EOMCC & $\begin{array}{l}\text { O-dMe } \\
\text { Dext }\end{array}$ & $10 \mathrm{H}$ Buf & $6 \mathrm{OHT}$ & $1 \mathrm{OHM}$ & $4 \mathrm{OH} \mathrm{M}$ & $3 \mathrm{OH} \mathrm{Q}$ & $\mathrm{N}$-dMe E & & & $17-\mathrm{OH}$ & 17,20 \\
\hline WT & 100 & 100 & 100 & 100 & 100 & 100 & 100 & 100 & 100 & 100 & 100 & 100 \\
\hline Q153R & 128 & 198 & 153 & 129 & 94 & 92 & 150 & 76 & 144 & 284 & 31 & 27 \\
\hline A287P & Nil & 27 & 24 & 17 & 17 & 14 & 3 & $\mathrm{Nil}$ & Nil & $\mathrm{Nil}$ & 40 & 21 \\
\hline $\mathrm{R} 457 \mathrm{H}$ & Nil & Nil & Nil & Nil & Nil & Nil & 1 & Nil & Nil & Nil & 3 & Nil \\
\hline A503V & 85 & 62 & 53 & 77 & 61 & 74 & 89 & 97 & 85 & 113 & 68 & 58 \\
\hline
\end{tabular}

The CYP enzymes listed on the top row were incubated with the substrates shown on the second row with electron donation via the POR sequence variants listed in the left column. Enzymatic efficiencies were calculated as Vmax/Km and compared to the corresponding value obtained with wild type (WT) POR, which is set as 100\%; the vertical columns list the \% of WT activity for each combination of P450 enzyme, POR variant, and substrate. EOMCC is 2H-1-benzopyran-3-carbonitrile,7-(ethoxy-methoxy)-2-oxo-(9Cl), a widely used synthetic fluorescent compound activated by many P450 enzymes; it is not a drug, but the reaction is easily assayed.

O-dMe Dext, O-demethylation of dextromethorphan; $1 \mathrm{OH}$ Buf, 1-hydroxylation of bufuralol; $6 \mathrm{OH}$ T, $6 \beta$-hydroxylation of testosterone; $1 \mathrm{OH}$ M, 1-hydroxylation of midazolam; $4 \mathrm{OH}$ M, 4-hydroxylation of midazolam; $3 \mathrm{OH}$ Q, 3-hydroxylation of quinidine; N-dMe E, N-demethylation of erythromycin; $170 \mathrm{H}, 17$ a-hydroxylation of progesterone; 17,20, conversion of 17a-hydroxypregnenolone to DHEA. 
group and hence cannot transfer electrons. ${ }^{93)}$ With human P450c17, b5 selectively stimulates 17,20-lyase activity but has negligible effects on 17 -hydroxylase activity. ${ }^{94,95)}$

Substantial evidence indicates that b5 enhances the interaction of $\mathrm{P} 450 \mathrm{c} 17$ and POR, promoting more efficient electron transfer. ${ }^{94,95)}$ This mechanism would account for b5 having no effect on the $\mathrm{Km}$ of P450c17, while increasing the Vmax of the 17,20-lyase reaction. ${ }^{69,94,95)}$ It is consistent with data showing that excess POR increases 17,20-lyase activity in the absence of $\mathrm{b} 5,{ }^{96,97)}$ and that mutations in the POR binding site of $\mathrm{P} 450 \mathrm{c} 17$ selectively reduced 17,20 -lyase activity. ${ }^{69)}$ Additionally, when the molar ratio of b5 to $\mathrm{P} 450 \mathrm{c} 17$ is fixed, 17,20-lyase activity shows a dose-response to added POR ${ }^{95}$; a dose-response was also observed in the absence of b5, but 17,20-lyase activity was always higher in the presence of b5, confirming that b5 augments 17,20-lyase activity by facilitating electron transfer from POR ${ }^{95)}$ Alternatively, b5 could promote 17,20-lyase activity by inducing a conformational change in $\mathrm{P} 450 \mathrm{c} 17$ that might promote the interaction of steroid carbon number 20 (C20), rather than $\mathrm{C} 17$, with the heme iron of P450c17. ${ }^{98)}$ Such b5-induced conformational changes with changes in activity have been reported with other P450 enzymes. A modest b5-induced change in the conformation of the substrate-binding pocket of $\mathrm{P} 450 \mathrm{c} 17$ has been reported, ${ }^{99)}$ and at least one mutation in the active site of $\mathrm{P} 450 \mathrm{c} 17$ has been reported to impair 17,20 -lyase activity selectively. ${ }^{100)}$ Thus, both mechanisms appear to be involved.

The 17,20-lyase activity of P450c17 can also be increased by the serine/threonine phosphorylation of $\mathrm{P} 450 \mathrm{c} 17,{ }^{101,102)}$ probably catalyzed by $\mathrm{p} 38 \mathrm{a}$, a cAMP-dependent mitogenactivated protein kinase, ${ }^{103}$ apparently increasing the association of P450c17 with POR, ${ }^{95)}$ Genetic and biochemical studies implicate positively charged residues in P450c17, including R347, R358 (and perhaps R449 and K89) in its interaction with $\mathrm{b} 5^{68,69)}$; correspondingly, residues E48 and E49 of b5 are required for high 17,20-lyase activity. ${ }^{104)}$ Thus, the regulation of 17,20-lyase activity, and consequently of androgen production, depends on factors that facilitate the flow of electrons to P450c17: high concentrations of POR, the presence of b5, and serine phosphorylation of P450c17. ${ }^{105}$

\section{Mutation of b5}

Mutations of P450c17 R347 or R358, which disrupt electron transfer from POR, were the first form of 17,20-lyase deficiency to be demonstrated genetically and biochemically. ${ }^{68)}$ This prompted a broader search for mutations in factors affecting electron transport as potential causes of 17,20-lyase deficiency. The first case of b5 deficiency was reported in a patient with methemoglobiemia and ambiguous genitalia, but unfortunately no studies of adrenal or gonadal steroidogenesis were reported. ${ }^{106,107)}$ Methemoglobinemia is a predictable consequence of $\mathrm{b} 5$ deficiency, as the reduction of methemoglobin is the principal physiologic role of b5, and the common cause of methemoglobiemia is deficiency of b5 reductase. More recently, a consanguineous 46,XY infant was reported who had micropenis, bifid scrotum, scrotal hypospadias, and homozygous b5 mutation W27X. ${ }^{108)}$ By age 3 months he had hypergonadotropic hypogonadism with low adrenal and gonadal C19 steroids and a normal cortisol response to ACTH; the methemoglobin level was 4 -fold above the upper limit of normal, but clinical methemoglobinemia was not apparent. Cytochrome b5 residues E48 and E49, which are required to stimulate 17,20-lyase activity, are absent with the W27X mutation; the residues required for the reduction of methemoglobin have not been mapped, but this activity should require heme binding. Since these reports, a small number of additional patients have been characterized. ${ }^{109-111)}$ Thus, b5 deficiency is an important cause of 17,20-lyase deficiency that does not appear to affect cortisol synthesis, whereas specific P450c17 mutations and the one reported POR mutation that presented as 17,20-lyase deficiency ${ }^{64)}$ may have residual cortisol synthesis. ${ }^{105)}$

\section{Conclusion}

Disorders in the factors that participate in electron transfer from NADPH to cytochrome P450 enzymes are a newly recognized group of disorders of steroidogenesis. Mutations in POR, first described in 2004, are fairly common and are now well-characterized clinically, genetically and biochemically. Mutations in b5 were first described in 2010, causing isolated 17,20-lyase deficiency, but this remains one of the rarest disorders in steroidogenesis. Mutations in FdxR were first reported in 2017 and cause neuropathic hearing loss and visual impairment, but potential (probable) steroidogenic consequences have not been reported or sought. As Fdx and FdxR are essential components in the synthesis of Fe-S clusters, a neurologic phenotype is not surprising. Careful clinical studies of adrenal and gonadal steroidogenesis in these patients are needed, as are in vitro studies of steroidogenesis with recapitulation of the known FdxR mutations in conjunction with a mitochondrial P450 enzyme such as P450scc.

\section{Conflicts of interest}

No potential conflict of interest relevant to this article was reported.

\section{Acknowledgments}

Work done in the author's laboratory was supported by grants from the National Institutes of Health and from private foundations.

\section{References}

1. Miller WL, Auchus RJ. The molecular biology, biochemistry, and physiology of human steroidogenesis and its disorders. 
Endocr Rev 2011;32:81-151.

2. Kim CJ. Congenital lipoid adrenal hyperplasia. Ann Pediatr Endocrinol Metab 2014;19:179-83.

3. Sahakitrungruang T. Clinical and molecular review of atypical congenital adrenal hyperplasia. Ann Pediatr Endocrinol Metab 2015;20:1-7.

4. Choi JH, Kim GH, Yoo HW. Recent advances in biochemical and molecular analysis of congenital adrenal hyperplasia due to 21-hydroxylase deficiency. Ann Pediatr Endocrinol Metab 2016;21:1-6.

5. Miller WL. Disorders in the initial steps in adrenal steroidogenesis. J Steroid Biochem Mol Biol 2017;165:18-37.

6. Miller WL. Genetic disorders of vitamin D biosynthesis and degradation. J Steroid Biochem Mol Biol 2017;165:1018 .

7. Miller WL. Molecular biology of steroid hormone synthesis. Endocr Rev 1988;9:295-318.

8. Voutilainen R, Tapanainen J, Chung B, Matteson KJ, Miller WL. Hormonal regulation of P450scc (20,22 desmolase) and P450c17 (17 -hydroxylase/17,20 lyase) in cultured human granulosa cells. J Clin Endocrinol Metab 1986;63:202-7.

9. Miller WL, Bose HS. Early steps in steroidogenesis: Intracellular cholesterol trafficking. J Lipid Res 2011;52: 2111-35.

10. Bose HS, Lingappa VR, Miller WL. Rapid regulation of steroidogenesis by mitochondrial protein import. Nature 2002;417:87-91.

11. Toaff ME, Schleyer H, Strauss JF 3rd. Metabolism of 25-hydroxycholesterol by rat luteal mitochondria and dispersed cells. Endocrinology 1982;111:1785-90.

12. Bose HS, Whittal RM, Huang MC, Baldwin MA, Miller WL. N-218 MLN64, a protein with StAR-like steroidogenic activity is folded and cleaved similarly to StAR. Biochemistry 2000;39:11722-31.

13. Cherradi N, Rossier MF, Vallotton MB, Timberg R, Friedberg I, Orly J, et al. Submitochondrial distribution of three key steroidogenic proteins (steroidogenic acute regulatory protein and cytochrome P450scc and $3 \beta$-hydroxysteroid dehydrogenase isomerase enzymes) upon stimulation by intracellular calcium in adrenal glomerulosa cells. J Biol Chem 1997;272:7899-907.

14. Ortiz de Monellano PR. Hydrocarbon hydroxylation by cytochrome P450 enzymes. Chem Rev 2010;110:932-48.

15. Shaik S, Cohen S, Wang Y, Chen H, Kumar D, Thiel W. P450 Enzymes: their structure, reactivity, and selectivitymodeled by QM/MM Calculations. Chem Rev 2010;110: 949-1017.

16. Nebert DW, Wikvall K, Miller WL. Human cytochromes P450 in health and disease. Phil Trans Roy Soc B 2013;368:20120431.

17. Miller WL. Minireview. Regulation of steroidogenesis by electron transfer. Endocrinology 2005;146:2544-50.

18. Solish SB, Picado-Leonard J, Morel Y, Kuhn RW, Mohandas TK, Hanukoglu I, et al. Human adrenodoxin reductase: two mRNAs encoded by a single gene on chromosome
$17 \mathrm{cen} \rightarrow \mathrm{q} 25$ are expressed in steroidogenic tissues. Proc Natl Acad Sci USA 1988;85:7104-8.

19. Lin D, Shi Y, Miller WL. Cloning and sequence of the human adrenodoxin reductase gene. Proc Natl Acad Sci USA 1990;87:8516-20.

20. Coghlan VM, Vickery LE. Site-specific mutations in human ferredoxin that affect binding to ferredoxin reductase and cytochrome P450scc. J Biol Chem 1991;266:18606-12.

21. Brandt ME, Vickery LE. Expression and characterization of human mitochondrial ferredoxin reductase in Escherichia coli. Arch Biochem Biophys 1992;294:735-40.

22. Bak DW, Elliott SJ. Alternative FeS cluster ligands: tuning redox potentials and chemistry. Curr Opin Chem Biol 2014;19:50-8.

23. Braymer JJ, Lill R. Iron-sulfur biogenesis and trafficking in mitochondria. J Biol Chem 2017;292:12754-63.

24. Maio N, Rouault TA. Outlining the complex pathway of mammalian Fe-S cluster biogenesis. Trends Biochem Sci 2020;45:411-26.

25. Maio N, Jain A, Rouault TA. Mammalian iron-sulfur cluster biogenesis: recent insights into the roles of frataxin, acyl carrier protein and ATPase-mediated transfer to recipient proteins. Curr Opin Chem Biol 2020;55:34-44.

26. Zhang W, Xu L, Zhao H, Li K. Mammalian mitochondrial iron-sulfur cluster biogenesis and transfer and related human diseases. Biophys Rep 2021;7:127-41.

27. Rouault TA. Mammalian iron-sulphur proteins: novel insights into biogenesis and function. Nature Rev Mol Cell Biol 2015; 16:45-55.

28. Stehling O, Lill R. The role of mitochondria in cellular iron-sulfur protein biogenesis: mechanisms, connected processes, and diseases. Cold Spring Harbor Perspect Biol 2013;5:a011312.

29. Isaya G. Mitochondrial iron-sulfur cluster dysfunction in neurodegenerative disease. Front Pharmacol 2014;5:29.

30. Valentine RC. Bacterial ferredoxin. Bacteriol Rev 1964;28: 497-517.

31. Chashchin VL, Lapko VN, Adamovich TB, Kirillova NM, Lapko AG, Akhrem AA. The primary structure of hepatoredoxin from bovine liver mitochondria. Bioorg Khim 1986;12:1286-9.

32. Okamura T, John ME, Zuber MX, Simpson ER, Waterman MR. Molecular cloning and amino acid sequence of the precursor form of bovine adrenodoxin. Evidence for a previously unidentified $\mathrm{COOH}$-terminal peptide. Proc Natl Acad Sci USA 1985;82:5705-9.

33. Picado-Leonard J, Voutilainen R, Kao L, Chung B, Strauss JF 3rd, Miller WL. Human adrenodoxin: cloning of three cDNAs and cycloheximide enhancement in JEG-3 cells. J Biol Chem 1988;263:3240-4.

34. Mittal S, Zhu YZ, Vickery LE. Molecular cloning and sequence analysis of human placental ferredoxin. Arch Biochem Biophys 1988:264:383-91.

35. Chang CY, Wu DA, Lai CC, Miller WL, Chung BC. Cloning and structure of the human adrenodoxin gene. DNA 1988;7:609-15. 
36. Morel Y, Picado-Leonard J, Wu DA, Chang C, Mohandas TK, Chung B, et al. Assignment of the functional gene for adrenodoxin to chromosome $11 \mathrm{q} 13 \rightarrow$ qter and of two adrenodoxin pseudogenes to chromosome 20cen $\rightarrow$ q13.1. Am J Hum Genet 1988;43:52-9.

37. Sparkes RS, Klisak I, Miller WL. Regional mapping of genes encoding human steroidogenic enzymes: P450scc to 15q23-q24, adrenodoxin to $11 \mathrm{q} 22$, adrenodoxin reductase to $17 \mathrm{q} 24-\mathrm{q} 25$, and P450c17 to $10 \mathrm{q} 24-\mathrm{q} 25$. DNA Cell Biol 1991;10:359-65.

38. Qi W, Li J, Cowan JA. Human ferredoxin-2 displays a unique conformational change. Dalton Trans 2013;42:3088-91.

39. Sheftel AD, Stehling O, Pierik AJ, Elsasser HP, Muhlenhoff U, Webert H, et al. Humans possess two mitochondrial ferredoxins, Fdx1 and Fdx2, with distinct roles in steroidogenesis, heme, and $\mathrm{Fe} / \mathrm{S}$ cluster biosynthesis. Proc Natl Acad Sci USA 2010;107:11775-80.

40. Shi Y, Ghosh M, Kovtunovych G, Crooks DR, Rouault TA. Both human ferredoxins 1 and 2 and ferredoxin reductase are important for iron-sulfur cluster biogenesis. Biochim Biophys Acta 2012;1823:484-92.

41. Cai K, Tonelli M, Frederick RO, Markley JL. Human mitochondrial ferredoxin 1 (FDX1) and ferredoxin 2 (FDX2) both bind cysteine desulfurase and donate electrons for iron-sulfur cluster biosynthesis. Biochemistry 2017;56:487-99.

42. Griffin A, Parajes S, Weger M, Zaucker A, Taylor AE, O'Neil DM, et al. Ferredoxin $1 \mathrm{~b}(\mathrm{Fdxlb})$ is the essential mitochondrial redox partner for cortisol biosynthesis in zebrafish. Endocrinology 2016;157:1122-34.

43. Oakes JA, Li N, Wistow BRC, Griffin A, Barnard L, Storbeck KH, et al. Ferredoxin 1b deficiency leads to testis disorganization, impaired spermatogenesis and feminization in zebrafish. Endocrinology 2019;160:240116.

44. Spiegel R, Saada A, Halvardson J, Soiferman D, Shaag A, Edvardson S, et al. Deleterious mutation in FDX1L gene is associated with a novel mitochondrial muscle myopathy. Euro J Hum Genet 2014;22:902-6.

45. Gurgel-Giannetti J, Lynch DS, Paiva ARB, Lucato LT, Yamamoto G, Thomsen C, et al. A novel complex neurological phenotype due to a homozygous mutation in FDX2. Brain 2018;141:2289-98.

46. Brentano ST, Black SM, Lin D, Miller WL. cAMP posttranscriptionally diminishes the abundance of adrenodoxin reductase mRNA. Proc Natl Acad Sci USA 1992;89:4099103.

47. Paul A, Drecourt A, Petit F, Deguine DD, Vasnier C, Oufadem M, et al. FDXR mutations cause sensorial neuropathies and expand the spectrum of mitochondrial Fe-S-synthesis diseases. Am J Hum Genet 2017;101:630-7.

48. Peng Y, Shinde DN, Valencia CA, Mo JS, Rosenfeld J, Truitt Cho $\mathrm{M}$, et al. Biallelic mutations in the ferredoxin reductase gene cause novel mitochondriopathy with optic atrophy. Hum Mol Genet 2017;26:4937-50.

49. Slone J, Peng Y, Chamberlin A, Harris B, Kaylor J,
McDonald MT, et al. Biallelic mutations in FDXR cause neurodegeneration associated with inflammation. J Hum Genet 2018;63:1211-22.

50. Slone JD, Yang L, Yan Peng Y, Queme LF, Harris B, Rizzo SJS, et al. Integrated analysis of the molecular pathogenesis of FDXR-associated disease. Cell Death and Disease 2020;11:423.

51. Stenton SL, Piekutowska-Abramczuk D, Kulterer L, Kopajtich R, Claeys KG, Ciara E, et al. Expanding the clinical and genetic spectrum of FDXR deficiency by functional validation of variants of uncertain significance. Human Mutation 2021;42:310-9.

52. Jurkute N, Shanmugarajah PD, Hadjivassiliou M, Higgs J, Vojcic M, Horrocks I, et al. Expanding the FDXR-associated disease phenotype: retinal dystrophy is a recurrent ocular feature. Invest Ophthalmol Vis Sci 2021;62:2.

53. Fairfield H, Srivastava A, Ananda G, Liu R, Kircher M, Lakshminarayana A, et al. Exome sequencing reveals pathogenic mutations in 91 strains of mice with Mendelian disorders. Genome Res 2015;25:948-57.

54. Baker BY, Lin L, Kim CJ, Raza J, Smith CP, Miller WL, et al. Non-classic congenital lipoid adrenal hyperplasia: a new disorder of the steroidogenic acute regulatory protein with very late presentation and normal male genitalia. J Clin Endocrinol Metab 2006;91:4781-5.

55. Sahakitrungruang T, Tee MK, Blackett PR, Miller WL. Partial defect in the cholesterol side-chain cleavage enzyme, P450scc (CYP11A1) resembling non-classic congenital lipoid adrenal hyperplasia. J Clin Endocrinol Metab 2011;96:792-8.

56. Pandey AV, Flück CE. NADPH P450 oxidoreductase: structure, function, and pathology of diseases. Pharmacol Therap 2013;138:229-54.

57. Wang M, Roberts DL, Paschke R, Shea TM, Masters BS, Kim JJ. Three-dimensional structure of NADPH-cytochrome P450 reductase: prototype for FMN- and FAD-containing enzymes. Proc Natl Acad Sci USA 1997;94:8411-6.

58. Ellis J, Gutierrez A, Barsukov IL, Huang WC, Grossmann JG, Roberts GC. Domain motion in cytochrome P450 reductase: conformational equilibria revealed by NMR and small-angle x-ray scattering. J Biol Chem 2009;284:3662837.

59. Shen AL, O'Leary KA, Kasper CB. Association of multiple developmental defects and embryonic lethality with loss of microsomal NADPH-cytochrome P450 oxidoreductase. J Biol Chem 2002;277:6536-41.

60. Otto DM, Henderson CJ, Carrie D, Davey M, Gundersen TE, Blomhoff R, et al. Identification of novel roles of the cytochrome P450 system in early embryogenesis: effects on vasculogenesis and retinoic acid homeostasis. Mol Cell Biol 2003;23:6103-16.

61. Flück CE, Tajima T, Pandey AV, Arlt W, Okuhara K, Verge CF, et al. Mutant P450 oxidoreductase causes disordered steroidogenesis with and without Antley-Bixler syndrome. Nature Genetics 2004;36:228-30.

62. Huang N, Pandey AV, Agrawal V, Reardon W, Lapunzina 
PD, Mowat D, et al. Diversity and function of mutations in P450 oxidoreductase in patients with Antley-Bixler syndrome and disordered steroidogenesis. Am J Hum Genet 2005;76:729-49.

63. Laue K, Pogoda HM, Daniel PB, van Haeringen A, Alanay Y, von Ameln S, et al. Craniosynostosis and multiple skeletal anomalies in humans and zebrafish result from a defect in the localized degradation of retinoic acid. Am J Hum Genet 2011;89:595-606.

64. Hershkovitz E, Parvari R, Wudy SA, Hartmann MF, Gomes LG, Loewental N, et al. Homozygous mutation G539R in the gene for P450 oxidoreductase in a family previously diagnosed as having 17,20 lyase deficiency. J Clin Endocrinol Metab 2008;93:3584-8.

65. Sahakitrungruang T, Huang N, Tee MK, Agrawal V, Russell WE, Crock P, et al. Clinical, genetic and enzymatic characterization of P450 oxidoreductase deficiency in four patients. J Clin Endocrinol Metab 2009;94:4992-5000.

66. Fukami M, Horikawa R, Nagai T, Tanaka T, Naiki Y, Sato N, et al. Cytochrome $\mathrm{P} 450$ oxidoreductase gene mutations and Antley-Bixler syndrome with abnormal genitalia and/or impaired steroidogenesis: molecular and clinical studies in 10 patients. J Clin Endocrinol Metab 2005;90:414-26.

67. Krone N, Reisch N, Idkowiak J, Dhir V, Ivison HE, Hughes $\mathrm{BA}$, et al. Genotype-phenotype analysis in congenital adrenal hyperplasia due to $\mathrm{P} 450$ oxidoreductase deficiency. J Clin Endocrinol Metab 2012;97:E257-67.

68. Geller DH, Auchus RJ, Mendonça BB, Miller WL. The genetic and functional basis of isolated 17,20 lyase deficiency. Nature Genet 1997;17:201-5.

69. Geller DH, Auchus RJ, Miller WL. P450c17 mutations R347H and R358Q selectively disrupt 17,20 lyase activity by disrupting interactions with P450 oxidoreductase and cytochrome b5. Mol Endocrinol 1999;13:167-75.

70. Adachi M, Tachibana K, Asakura Y, Yamamoto T, Hanaki $\mathrm{K}$, Oka A. Compound heterozygous mutations of cytochrome P450 oxidoreductase gene (POR) in two patients with Antley-Bixler syndrome. Am J Med Genet A 2004;128A:333-9.

71. Fukami M, Hasegawa T, Horikawa R, Ohashi T, Nishimura G, Homma K, et al. Cytochrome P450 oxidoreductase deficiency in three patients initially regarded as having 21-hydroxylase deficiency and/or aromatase deficiency: diagnostic value of urine steroid hormone analysis. Pediatr Res 2006;59:276-80.

72. Shackleton C, Marcos J, Arlt W, Hauffa BP. Prenatal diagnosis of P450 oxidoreductase deficiency (ORD): a disorder causing low pregnancy estriol, maternal and fetal virilization, and the Antley-Bixler syndrome phenotype. Am J Med Genet A 2004;129A:105-12.

73. Pandey AV, Kempna P, Hofer G, Mullis PE, Flück CE. 2007. Modulation of human CYP19A1 activity by mutant NADPH P450 oxidoreductase. Mol Endocrinol 2007;21:2579-95

74. Auchus RJ. The backdoor pathway to dihydrotestosterone. Trends Endocrinol Metab 2004;15:432-8.
75. Homma K, Hasegawa T, Nagai T, Adachi M, Horikawa R, Fujiwara I, et al. Urine steroid hormone profile analysis in cytochrome P450 oxidoreductase deficiency: implication for the backdoor pathway to dihydrotestosterone. J Clin Endocrinol Metab 2006;91:2643-9.

76. Huang N, Agrawal V, Giacomini KM, Miller WL. Genetics of P450 oxidoreductase: sequence variation in 842 individuals of four ethnicities and activities of 15 missense mutants. Proc Natl Acad Sci USA 2008;105:1733-8.

77. O'Leary KA, Li HC, Ram PA, McQuiddy P, Waxman DJ, Kasper CB. Thyroid regulation of NADPH:cytochrome P450 oxidoreductase: identification of a thyroid-responsive element in the 5'-flank of the oxidoreductase gene. Mol Pharmacol 1997;52:46-53.

78. Li HC, Liu D, Waxman DJ. Transcriptional induction of hepatic NADPH: cytochrome P450 oxidoreductase by thyroid hormone. Mol Pharmacol 2001;59:987-95.

79. Tee MK, Huang N, Damm I, Miller WL. Transcriptional regulation of human $\mathrm{P} 450$ oxidoreductase: identification of transcription factors and influence of promoter polymorphisms. Mol Endocrinol 2011;25:715-31.

80. Gomes LG, Huang N, Agrawal V, Mendonca BB, Bachega TASS, Miller WL. The common P450 oxidoreductase variant $\mathrm{A} 503 \mathrm{~V}$ is not a modifier gene for 21-hydroxylase deficiency. J Clin Endocrinol Metab 2008;93:2913-6.

81. Agrawal V, Huang N, Miller WL. Pharmacogenetics of P450 oxidoreductase. Effect of sequence variants on activities of CYP1A2 and CYP2C19. Pharmacogenet Genomics 2008; 18:569-76.

82. Ingelman-Sundberg M. Polymorphism of cytochrome P450 and xenobiotic toxicity. Toxicology 2002;181182:447-52.

83. Weinshilboum R. Inheritance and drug response. N Engl J Med 2003;348:529-37.

84. Williams PA, Cosme J, Vinkovic DM, Ward A, Angove HC, Day PJ, et al. Crystal structures of human cytochrome P450 3A4 bound to metyrapone and progesterone. Science 2004;305:683-6.

85. Ekroos M, Sjogren T. Structural basis for ligand promiscuity in cytochrome P450 3A4. Proc Natl Acad Sci USA 2006;103:13682-7.

86. Agrawal V, Choi JH, Giacomini KM, Miller WL. Substratespecific modulation of CYP3A4 activity by genetic variants of cytochrome P450 oxidoreductase (POR). Pharmacogenet Genomics 2010;20:611-8.

87. Sandee D, Morrissey K, Agrawal V, Tam HK, Kramer MA, Tracy TS, et al. Effects of genetic variants of P450 oxidoreductase on catalysis by CYP2D6 in vitro. Pharmacogenet Genomics 2010;20:677-86.

88. Miller WL, Agrawal V, Sandee D, Tee MK, Huang N, Choi JH, et al. Consequences of POR mutations and polymorphisms. Mol Cell Endocrinol 2011;336:174-9.

89. Giordano S, Steggles A. The human liver and reticulocyte cytochrome b5 mRNA's are products from a single gene. Biochim Biophys Res Commun 1991;178:38-44.

90. Shephard EA, Povey S, Spurr NK, Phillips IR. Chromo- 
somal localization of a cytochrome b5 gene to human chromosome 18 and a cytochrome b5 pseudogene to the $\mathrm{X}$ chromosome. Genomics 1992;11:302-8.

91. Storbeck KH, Swart AC, Fox CL, Swart P. Cytochrome b5 modulates multiple reactions in steroidogenesis by diverse mechanisms. J Steroid Biochem Mol Biol 2015;151:66-73.

92. Bridges A, Gruenke L, Chang YT, Vakser IA, Loew GH, Waskell L. Identification of the binding site on cytochrome P450 2B4 for cytochrome b5 and cytochrome P450 reductase. J Biol Chem 1998;273:17036-49.

93. Yamazaki H, Johnson WW, Ueng YF, Shimada T, Guengerich FP. Lack of electron transfer from cytochrome b5 in stimulation of catalytic activities of cytochrome P450 3A4. Characterization of a reconstituted cytochrome P450 3A4/ NADPH-cytochrome P450 reductase system and studies of apo-cytochrome b5. J Biol Chem 1996;271:27438-44.

94. Auchus RJ, Lee TC, Miller WL. Cytochrome b5 augments the 17,20 lyase activity of human P450c17 without direct electron transfer. J Biol Chem 1998;273:3158-65.

95. Pandey AV, Miller WL. Regulation of 17,20 lyase activity by cytochrome b5 and by serine phosphorylation of $\mathrm{P} 450 \mathrm{c} 17$. J Biol Chem 2005;280:13265-71.

96. Yanagibashi K, Hall P. Role of electron transport in the regulation of the lyase activity of $\mathrm{C} 21$ side-chain cleavage P-450 from porcine adrenal and testicular microsomes. J Biol Chem 1986;26:8429-33.

97. Lin D, Black SM, Nagahama Y, Miller WL. Steroid 17a-hydroxylase and 17,20 lyase activities of P450c17: contributions of serine 106 and of P450 reductase. Endocrinology 1993;132:2498-506.

98. Lee-Robichaud P, Akhtar ME, Akhtar M. Lysine mutagenesis identifies cationic charges of human CYP17 that interact with cytochrome b5 to promote male sexhormone biosynthesis. Biochem J 1999;342:309-12.

99. Swart AC, Storbeck KH, Swart P. A single amino acid residue Ala 105, confers 16a-hydroxylase activity to human cytochrome P450 17a-hydroxylase/17,20 lyase. J Steroid Biochem Mol Biol 2010;119:112-20.

100. Sherbet DP, Tiosano D, Kwist KM, Hochberg Z, Auchus RJ. CYP17 mutation E305G causes isolated 17,20 lyase deficiency by selectively altering substrate binding. J Biol Chem 2003;278:48563-9.
101. Zhang L, Rodriguez H, Ohno S, Miller WL. Serine phosphorylation of human P450c17 increases 17,20 lyase activity: implications for adrenarche and for the polycystic ovary syndrome. Proc Natl Acad Sci USA 1995;92:1061923.

102. Pandey AV, Mellon SH, Miller WL. Protein phosphatase 2A and phosphoprotein SET regulate androgen production by P450c17. J Biol Chem 2003;278:2837-44.

103. Tee MK, Miller WL. Phosphorylation of human cytochrome P450c17 by p38a selectively increases 17,20 lyase activity and androgen synthesis. J Biol Chem 2013;288:23903-13.

104. Naffin-Olivos JL, Auchus RJ. Human cytochrome b5 requires residues E48 and E49 to stimulate the 17,20-lyase activity of cytochrome P450c17. Biochemistry 2006;24:755-62.

105. Miller WL. The syndrome of 17,20 lyase deficiency. J Clin Endocrinol Metab 2012;97:59-67.

106. Hegesh E, Hegesh J, Kaftory A. Congenital methemoglobinemia with deficiency of cytochrome b5. New England J Med 1986;314:757-61.

107. Giordano SJ, Kaftory A, Steggles AW. A splicing mutation in the cytochrome b5 gene from a patient with congenital methemoglobinemia and pseudohermaphroditism. Human Genet 1994;93:568-70.

108. Kok RC, Timmerman MA, Wolfenbuttel KP, Drop SLS, deJong FH. Isolated 17,20 lyase deficiency due to the cytochrome b5 mutation W27X. J Clin Endocrinol Metab 2010;95:994-9.

109. Idkowiak J, Randell T, Dhir V, Patel P, Shackleton CH, Taylor NF, et al. A missense mutation in the human cytochrome b5 gene causes 46,XY disorder of sex development due to true isolated 17,20 lyase deficiency. J Clin Endocrinol Metab 2012;97:E465-75.

110. Leung MT, Cheung HN, Iu YP, Choi CH, Tiu SC, Shek CC. Isolated 17,20-lyase deficiency in a CYB5A mutated female with normal sexual development and fertility. J Endocr Soc 2020;4:1-8

111. Shaunak M, Taylor NF, Hunt D, Davies JH. Isolated 17,20 lyase deficiency secondary to a novel CYB5A variant: comparison of steroid metabolomic findings with published cases provides diagnostic guidelines and greater insight into its biological role. Horm Res Paediatr 2020;93:483-95. 